\title{
Misdiagnosis of hemifacial spasm is a frequent event in the primary care setting
}

\section{Erro diagnóstico do espasmo hemifacial é ocorrência frequente em unidades primárias de atenção à saúde}

\author{
Alberto R. M. Martinez', Marcelo B. Nunes ${ }^{1}$, Nayara D. Immich², Luiza Piovesana ${ }^{1}$, Marcondes França Jr.',
} Lidiane S. Campos' ${ }^{1}$, Anelyssa D’Abreu ${ }^{1}$

\begin{abstract}
Primary hemifacial spasm (HFS) is characterized by irregular and involuntary contraction of the muscles innervated by the ipsilateral facial nerve. Treatment controls symptoms and improves quality of life (QoL). Objective: Evaluate the initial diagnosis and treatment of HFS prior to referral to a tertiary center. Method: We interviewed through a standard questionnaire 66 patients currently followed in our center. Results: Mean age: $64.19 \pm 11.6$ years, mean age of symptoms onset: $51.9 \pm 12.5$ years, male/female ratio of 1:3. None of the patients had a correct diagnosis in their primary care evaluation. Medication was prescribed to $56.8 \%$. Mean time from symptom onset to botulinum toxin treatment: $4.34 \pm 7.1$ years, with a $95 \%$ satisfaction. Thirty percent presented social embarrassment due to HFS. Conclusion: Despite its relatively straightforward diagnosis, all patients had an incorrect diagnosis and treatment on their first evaluation. HFS brings social impairment and the delay in adequate treatment negatively impacts QoL.
\end{abstract}

Keywords: hemifacial spasm, misdiagnosis, botulinum toxin.

\section{RESUMO}

Espasmo hemifacial primário é caracterizado pela contração irregular ou involuntária dos músculos inervados pelo nervo facial ipsilateral. O tratamento é eficaz para controlar sintomas e melhorar a qualidade de vida. Objetivo: Avaliar diagnóstico e tratamento do espasmo hemifacial primário feitos antes do encaminhamento ao centro terciário. Método: Foram coletados retrospectivamente dados de 66 pacien-

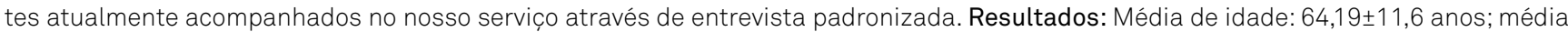
de idade no início dos sintomas: 51,9 $\pm 12,5$ anos; razão homem/mulher de 1:3. Nenhum dos pacientes foi corretamente diagnosticado na primeira avaliação. Foram prescritos medicamentos para 56,8\%. 0 tempo médio entre início dos sintomas e o tratamento com toxina botulínica foi 4,34 7,1 anos; 95\% ficaram satisfeitos com o tratamento; 30\% tinham constrangimento social. Conclusão: Embora seja uma condição de relativa facilidade diagnóstica, todos os pacientes tiveram diagnóstico e tratamento incorretos na primeira avaliação. Espasmo hemifacial primário traz constrangimento social, agravado pelo atraso no tratamento adequado.

Palavras-chave: espasmo hemifacial, diagnóstico, toxina botulínica.

Hemifacial spasm (HFS) is a peripherally-induced movement disorder characterized by progressive, involuntary and a painless form of a segmental myoclonus expressed by tonic or clonic unilateral facial muscle contractions in the territory innervated by ipsilateral seventh cranial nerve ${ }^{1-3}$. Generally the muscle twitch involves initially the periocular region but as it progresses, virtually all facial muscles could be affected ${ }^{3-5}$.

First described by Schültze in 1875, in a 56-year-old man with a 10-year history of involuntary movements involving the left side of the face ${ }^{6}$, HFS has been reported in large series of cases worldwide, the age-adjusted annual incidence was 0.78/100.000 in a study in Rochester and Olmsted County Minnesota $^{7}$ and the overall prevalence is about $10 / 100.000^{1,8,9}$.

Compression of the facial nerve at the root exit zone generally by vascular abnormalities is the most accepted hypothesis for HFS etiology ${ }^{3,4}$. Chung and cols described 1642 patients with HFS in which vascular compression of the facial nerve was responsible for $99.4 \%$ of the cases. The remaining

'Departamento de Neurologia, Universidade Estadual de Campinas, Sao Paulo SP, Brazil;

¿Universidade Comunitária da Região de Chapecó, Chapecó SC, Brazil.

Correspondence: Anelyssa D’Abreu, Departamento de Neurologia - UNICAMP. Rua Tessália Vieira de Camargo, 126; $13083-887$ Campinas SP, Brasil. E-mail: anelyssa@gmail.com

Conflicts of interest: Dr D’Abreu received a travel grant from Roche last year, Dr Luiza Piovesana e Dr Lidiane Campos received grants from Ipsen. All other authors have nothing to disclose.

Received 21 May 2013; Received in final form 24 October 2013; Accepted 31 October 2013. 
cases $(0.6 \%)$ were composed by masses or arterivenous malformation ${ }^{10}$. Although the vascular etiology is accepted, the evidence of a neurovascular conflict is present in $25 \%$ of asymptomatic subjects, leading to the fact that the HFS could not be explained only by the neurovascular compression ${ }^{1,8}$.

Although not life threatening, the paroxystic and chronic facial contractions in HFS significantly interferes in the activities of daily living and social activities with a major impact in quality of life (QoL) $)^{5,11,12}$. Psychiatric disorders such as obsessive symptoms are also associated to HFS ${ }^{13}$. Treatment options vary from surgical with a microvascular decompression procedure to botulinum toxin (BoNT) injections, the last accepted as the first treatment option considering the potential risks of a neurosurgical treatment ${ }^{1}$.

Hence, the delay in the diagnosis is unacceptable. HFS is highly detrimental to social functioning and QoL and the condition is easily investigated and treated. In this study, we aim to access the misdiagnoses of the HFS patients prior to referral to a tertiary movement disorder clinic.

\section{METHOD}

A retrospective study was performed through the review of the medical records which included the referral forms from the primary care centers and therefore the diagnosis made, if there was any. These data were complemented by a systematic interview of 66 patients diagnosed with HFS and followed in a Tertiary Movement Disorders Outpatient Clinic at the University Hospital of UNICAMP, São Paulo, Brazil. Data collected from the 66 patients included: general demographics; time from onset of symptoms and diagnosis of HFS; diagnosis given prior to HFS; treatment established prior to BoNT and its efficacy; time from diagnosis and BoNT treatment; years of BoNT treatment and satisfaction with it; review of employment history and social impairment due to HFS and the perception of the patients themselves about their condition considering what they were told in previous consultations. For statistical analysis we used Systat 9. Demographic and clinical data are presented in measures of central tendency (mean) and dispersion (standard deviation). This study was approved by the Ethical Committee of UNICAMP no. $924 / 2010$.

\section{RESULTS}

We included 50 female patients $(75.7 \%)$ and 16 male patients $(24.3 \%)$. The mean age at time of interview was $64.19 \pm 11.6$ years ranging from 31 to 84 years. Mean age of symptoms onset was $51.9 \pm 12.5$ years (range 13-75) and mean time from first symptom to proper HFS diagnosis was $2.64 \pm 3.8$ years $(0-20$ years). Total time in years since HFS
Table. Demographic data of 66 patients with HSF.

\begin{tabular}{lc}
\hline Age $(y)$ & $64.19 \pm 11.6(31-84)$ \\
Sex (M:F) & $1: 3$ \\
Age at HFS onset $(y)$ & $51.9 \pm 12.5(13-75)$ \\
Duration of HFS $(y)$ & $12.4 \pm 10.1(1.08-64)$ \\
Mean time from symptoms to BoNT injections (y) & $5.34 \pm 7.1(0-20)$ \\
Follow-up with BoNT (y) & $7.1 \pm 6$ \\
BoNT personal satisfaction (\%) & 95
\end{tabular}

onset to the last evaluation was $12.4 \pm 10.1$ (1.08-64 years). Demographic data is summarized in Table.

None of the patients had HFS as their first diagnosis. All patients were seen by their family physicians or a general practitioner. Surprisingly, 29 of out 66 (43.9\%) not even received a differential diagnosis at the primary care services and, for those who did, the most frequent hypothesis were: functional disorder (or psychogenic) in 25/66 (37.8\%), facial palsy in 6/66 (9\%), tics in 2/66 (3\%) and a miscellaneous group (Figure). In some cases, more than one "hypothesis" was made. When the patients were asked about their perception regarding their condition from the consultations prior to the referral, most of them (61 patients) were not able to describe their diagnosis and some reported anecdotal diagnosis, such as dental issues (2 cases), "aging issues" (1 case), vitamin deficiency (1 case) or "brain failure" (1 case).

Before referral, the initial treatment option was a prescription medicine in 35/66 (53\%) of cases, which included benzodiazepines in $25.36 \%$, anxiolytics in $17.9 \%$, carbamazepine in $8.9 \%$, vitamins and antihypertensive drugs. Among these patients receiving oral medication, 6/35 (17\%) referred partial or transient improvement of facial contractions, but none had a sustained response. Two patients were referred for surgical evaluation and two underwent dental extraction for symptomatic improvement.

Prior to botulinum toxin A (BoNT) injections, 31/66 patients opted to start oral medication, but only $17 \%$ presented a partial response. BoNT injections were scheduled as soon as they were referred to the Tertiary Movement Disorders Clinic. Mean time from symptom onset to BoNT treatment was 5.34 \pm 7.1 years (range 0-20). Ninety-five percent of the

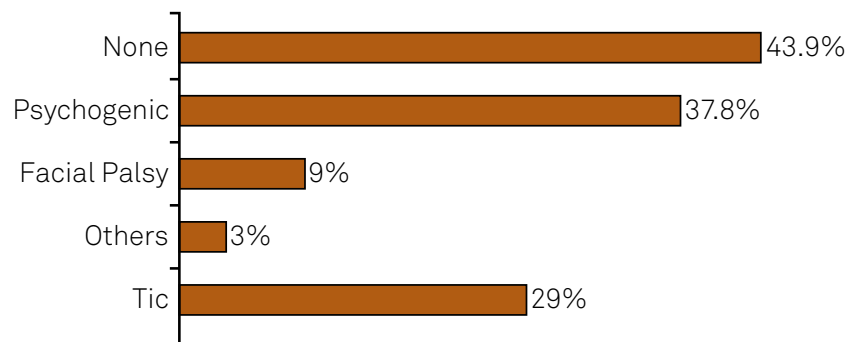

Figure. Different first diagnosis of hemifacial spasm patients. Some cases had more than one wrong hypothesis. 
patients were satisfied with their current treatment after a mean follow-up of $7.1 \pm 6$ years.

By the time patients arrived at our center, $50 \%$ of them were unemployed, and during the followup, $30 \%$ still complained of limiting social activities because of the HFS.

\section{DISCUSSION}

Even though HFS is not a common disease, with an estimated prevalence of $10 / 100000^{1,7,9}$, the diagnosis of HFS is imminently based on clinical grounds. As far as we know, this is the first study to evaluate the accuracy of the diagnosis at the first assessment and the time elapsed between the first evaluation and the use of the correct treatment. The general demographic data of the sample presented is consistent with previous HFS series ${ }^{1,3,4,10,13}$, although the mean age of symptoms onset was slightly higher than in another study in a Brazilian population ${ }^{18}$.

Tan and cols ${ }^{19}$ made a video evaluation among 209 family physicians showing 2 patients with HFS and inquiring about the correct diagnosis and treatment. Only 9.4\% (19/203) made the correct diagnosis, while the others either gave the wrong diagnosis or opted for the "don't know" answer.

Some semiological tools are helpful in order to make the correct diagnosis. Stamey and Jankovic tested "the other Babinski sign" or "the brow-lift sign" ("when orbicularis oculi contracts and the eye closes, the internal part of the frontalis contracts at the same time, the eyebrow rises during eye occlusion," and "this set of occurrences is impossible to reproduce by will” ). The authors found that the sign's sensitivity to diagnose HFS was $25.3 \%$, specificity was $100 \%$, and positive predictive value was $100 \%^{14}$.

Although easily recognized by a trained neurologist, the list of possible differential diagnosis for HFS includes tics, myokymia, blepharospasm, tardive dyskinesia, focal seizure, masticatory spasm, cranial dystonia and others ${ }^{1,3,8}$.
In our sample, a significant proportion of our patients not even received a single diagnostic hypothesis in $43.9 \%$ of patients, referring them to the tertiary center for investigation of facial movements. Most patients who received one, had a diagnosis of a functional movement disorder (psychogenic) which led to a significant delay in proper treatment. Even though psychiatric symptoms, such as obsessive and compulsive symptoms, have been described in a Brazillian series of HFS patients ${ }^{13}$, a psychogenic etiology was not found in any of our patients.

The treatment options for HFS patients include: simple massage, oral medication, microvascular decompression and regular BoNT injections, which is considered the first line treatment ${ }^{1,3,5}$. Medication used to HFS includes carbamazepine, clonazepam, phenytoin, gababentin and baclofen with a mild clinical response verified in other series varying from 8 to $16.6 \%{ }^{1,3,8}$. Our series showed similar data with a mild/transient medication response in $17 \%$ of those who received oral medication. A proportion of patients received oral treatment with a large array of medications even though they did not receive a diagnosis. BoNT injections reached good/excellent results in $76-100 \%$ of patients according to previous series ${ }^{1,10,18}$.

Misdiagnosis leads to a direct impact in QoL, social distress and impairment in activities of daily living such as driving or reading ${ }^{3,5,10,11}$. Nearly $50 \%$ of the patients evaluated in this series were unemployed by the time they reached the tertiary center and considered HFS as a contributing factor for this status. A third was still facing social limitations attributed to HFS.

Although HFS is not a life-threatening condition, it brings significant social and physical impairment that is greatly prolonged by an incorrect diagnosis. Prescription medication can bring a mild symptomatic relief, but BoNT injections lead to a much higher rate of personal satisfaction. Continuous education in the most prevalent movement disorders should be encouraged on primary care grounds in order to diminish unnecessary delay in treatment and diagnosis.

\section{References}

1. Kenney C, Jankovic J. Botulinum toxin in the treatment of blepharospasm and hemifacial spasm. J Neural Transm 2008;115:585-591.

2. Tan EK, Chan LL. Clinico-radiologic correlation in unilateral and bilateral hemifacial spasm. J Neurol Sci 2004;222:59-64.

3. Wang A, Jankovic J. Hemifacial spasm: clinical findings and treatment. Muscle Nerve; 1998; 21:1740-1747.

4. Ho SL, Cheng PW, Wong WC, et al. A case-controlled MRI/MRA study of neurovascular contact in hemifacial spasm. Neurology 1999;53:21322139.

5. Rudzinska M, Wójcik M, Szczudlik A. Hemifacial spasm non-motor and motor-related symptoms and their response to botulinum toxin therapy. J Neural Transm 2010;117:765-772.
6. Colosimo C, Berardelli A. An early image of hemifacial spasm: édouardbrissaud contribution. Mov Disord 2010;25:531-533.

7. Auger RG, Whisnant JP. Hemifacial spasm in Rochester and Olmstead County, Minnesota, 1960 to 1984. Arch Neurol 1990;47:1233-1234.

8. Tan N-C, Chan L-L, Tan E-K. Hemifacial spasm and involuntary facial movements. Q J Med 2002;95:493-500.

9. ChanL-L, Ng K-M, Fook-Chong S, Lo Y-L, Tan E-K. Three-dimensional MR volumetric analysis of the posterior fossa CSF space in hemifacial spasm. Neurology 2009;3:1054-1057.

10. Han I-B, Chang JH, Chang JW, Huh R, Chung SS. Unusual causes and presentations of hemifacial spasm. Neurosurgery 2009;65:130-137. 
11. Tan E-K, Fook-Chong S, Lum S-Y, Lim E. Botulinum toxin improves quality of life in hemifacial spasm: validation of a questionnaire (HFS3 0). J Neurol Sci 2004;219:151-155.

12. Jankovic J. Peripherally Induced Movement Disorders. Neurol Clin 2009;27:821-832.

13. Munhoz RP, Teive HAG, Coletta MVD, et al. Frequency of obsessive and compulsive symptoms in patients with blepharospasm and hemifacial spasm. Arq Neuropsiquiatr 2005;63:213-216.

14. Stamey W, Jankovic J. The other Babinski sign in hemifacial spasm. Neurology 2007; 69:402-404.

15. Xie T, Zhang X-B, Li Q-P, Zhu W, Zhou H, Gu Y. Hemifacial spasm patient with ipsilateral total absence of common carotid artery, vertebral artery and aneurysm of the contralateral internal carotid artery. Surg Radiol Anat 2010;32:707-710.
16. Kollewe K, Mohammadi B, Dengler R, Dressler D. Hemifacial spasm and reinnervationsynkinesias: long-term treatment with either Botox or Dysport. J Neural Transm 2010;117:759-763.

17. Valls-Sole J. Electrodiagnostic studies of the facial nerve in peripheral facial palsy and hemifacial spasm. Muscle Nerve 2007;36:14-20.

18. Barbosa ER, Takada LT, Gonçalves LR, Costa RMPN, SilveiraMoriyama L, Chien HF. Botulinum toxin type A in the treatment of hemifacial spasm. An 11-year experience. Arq Neuropsiquiatr 2010;68:502-505.

19. Tan NC, Tan EK, Khin LW. Diagnosis and misdiagnosis of hemifacialspasm:a clinical and video study. J Clin Neurosc 2004;11:142-144. 